\title{
Relationship Between Waiting Time, Anxiety and Sleep Disturbances Among Saudi Parents of Children Admitted to Pediatric Intensive Care Unit
}

\author{
Eman Dawood ${ }^{1,2,3^{*}} \quad$ Rufa Mitsu $^{1,2} \quad$ Hind AlGhadeer $^{1,2} \quad$ Meaad Alanizi $^{4}$ \\ Reem Alshehri ${ }^{4}$ Shahad Almutairi ${ }^{4}$
}

1.College of Nursing, King Saud bin Abdulaziz University for Health Sciences, Riyadh, Saudi Arabia

2.King Abdulla International Medical Research Center, King Saud bin Abdulaziz University for Health Sciences, Saudi Arabia

3.Department of Psychiatric and Mental Health Nursing, College of Nursing, Menofyia University, Egypt 4.Undergraduate Nursing Student, College of Nursing, King Saud bin Abdulaziz University for Health Sciences, Riyadh, Saudi Arabia

\begin{abstract}
Parents of children admitted to PICU experience extreme level of anxiety. It is an extremely difficult process for parents to make a transition from parents of well-child to parents of acutely ill child. Aim: To identify the relationship between waiting time, anxiety and sleep disturbances among saudi parents of children admitted to pediatric intensive care unit. Methods: A cross sectional descriptive correlational study design was employed to conduct this study on a convienience sample of 115 adult parents of children admitted to the PICU. Participants were asked to complete three questionnaire survey including participant's demographic background, Spielberger State-Trait Anxiety Inventory, and a parental sleep disturbance questionnaire. An explanation about the purpose and the nature of the study was offered for each individual potential participant. Subjects were assured about the confidentiality of the collected data and that it will be only used by the researcher for the purpose of the current study. Data were analyzed using SPSS version 22. Results: More than half of the participants (62.6\%) scored 12 and above reflecting considerable levels of anxiety. A very significant precentage $(92.7 \%)$ of the parents reported sleep problems. Three quarters of the participants (73.2\%) mentioned that sleep problems affected them negatively. There was a highly statistically significant difference between groups with different educational background in relation to anxiety, as well Unemployed participants experienced significantly higher anxiety. Conclusion: The findings of this exploratory study indicate considerable levels of anxiety and changes in sleep pattern of parents of children admitted to paediatric intensive care unit. During this period, identifying the parental needs and the causes of anxiety might contribute to parents' mental health.
\end{abstract}

Keywords: PICU, Parental Anxiety, waiting time, sleep disturbances

DOI: $10.7176 / \mathrm{JHMN} / 71-11$

Publication date: February $29^{\text {th }} 2020$

\section{Introduction}

Patient and family care approach to health care have beneficial collaboration between the patient, family and health care professionals. Most families prefer to be involved in majority of aspects of their child care, parents' satisfaction is an important indicator of quality care delivered for their children. However there are many challenges for promoting family's satisfaction especially in the pediatric intensive care units (PICU) where children's conditions are considered as life threating. Having a child admitted to the pediatric intensive care unit is one of the most stressful experiences for parents ${ }^{(1)}$.It is an extremely difficult process for parents to make a transition from parents of well-child to parents of acutely ill child ${ }^{(2)}$.

According to the statistics released by the Saudi minstry of health of the Saudi population, around $30 \%$ of the children up to 15 years are admitted to the PICU annually ${ }^{(3)}$.During hospitalization of their child parents experience extreme level of anxiety, they even approach near-panic level and significant disruption in their normal lives ${ }^{(4)}$. Impacts of child's hospitalization are not limited to only the parents but it extends to all siblings and other members of the family which reflects back on the parents who will be in a situation to cope with the change in the family function ${ }^{(1)}$. Several studies have estimated many stressors emanating from child's hospitalization that can influence parent's psychological status including hospital environment, uncertainty of the child's condition, intensive procedure, physical separation and alteration in parental roles ${ }^{(5)}$. In Mangalore, a study conducted to examine the relationship of demographic variables with their stress concluded that age, gender, socioeconomic status, residential area, number and age of children did not affect level of stress ${ }^{(1)}$. Another study about parental stress conducted in Punjab revealed that mothers and young parents were more stressed ${ }^{(6)}$. Additionally, another study conducted concluded that following child's admission to the PICU, parents experience high level of anxiety. Despite the high-parental anxiety, physician failed to notice that in nearly one third of parents ${ }^{(7)}$.

Admission of children to PICU is a crucial time to parents that may lead to different psychological distress 
including anxiety, sleep disturbances, and emotional stress. Sleep disturbances like unhealthy sleep patterns, insuficient duration of sleep and recurrent interuptions are the most common problems occurs to parents during hospitalization of their children. It can be referred to multiple factors such as the duration of stay in the hospital, child's condition and hospital environment ${ }^{(8)}$.

The negative effects of sleep deficiency on mothers and father's ability to handle it during that challenging time needed more examination and interference ${ }^{(9)}$. A research conducted in the pediatric intensive care unit (PICU) to assess the factors distressing the sleep of parents of severely ill children identified seven items that have impact on sleep such as the child's condition, being at the bedside or not, difficult thoughts and feelings, changes to usual sleep, caring for self and family, hospital environment and access to sleep locations. These factors were defined then as strategies to improve sleep, that stresses on the necessity of nurses to discover with parents the exceptional barriers and facilitators of sleep inorder to reach a level of good sleep. Another study conducted in Canada, included 90 parents of acutely ill children found that more than a quarter of nights met standards for acute sleep deficiency, there was significant variability in the quantity of nighttime sleep that individual subjects slept on different nights, and sleep was split with a significant percentage of the night spent awake. Research team recommended to focus on interventions to improve parents' capability to sustain systematic sleep-wake patterns in the future research studies ${ }^{(10)}$

Another important concern is the parent waiting time for healthcare service is determined by the world health organization (WHO) as one of the key measurement of a responsive health care system that aims to provide timely care and to reduce harmful delays ${ }^{(11)}$. Waiting time for child admission and receiving thorough information about the child's medical problem is a principle issue that parents are in challenge to stand for ${ }^{(1)}$. Parents are subjected to a significant anxiety that can affect their health, behavior, as well as produce a long-term emotional problems. Relevant literature has shown that long waiting time in hospital is one cause for high stress and anxiety in parents evidenced by recognized parents' emotional distress in waiting room. Furthermore, not knowing the prognosis of child's condition again increases the level of anxiety in waiting room among parents ${ }^{(12)}$. The needs of parents are affected by hospital environment and the health care team. Positive hospital environmental can contribute to the reduction in the level of anxiety during long time waiting ${ }^{(13)}$.

Ulrich's theory of supportive hospital design emphasized that environmental stress is a major obstacle to healing and that hospitals can be designed to reduce stress and thereby help with recovery ${ }^{(14)}$. Considerable evidence has linked the hospital environment to parents psychological status and the waiting room included the need for privacy, adequate space, cleanness and safety ${ }^{(13)}$. The recognition of family needs in critical care units and meeting those needs is crucial that will promote reduction in the level of stress and anxiety in addition to promoting deeper understanding of their childs' condition ${ }^{(13)}$. Literature has yet to identify Muslim families needs in relation to religious beliefs and cultural values in critical care settings in Saudi Arabia ${ }^{(15)}$.

Hospital staff caring attitude towards child, parents, and their way of communication with parents proven to reduce patents' anxiety and stress. Although reports have described the global experience and needs of mothers and fathers in NICUs, the nature and content of the conversations between the healthcare team and the parents concerning withholding or withdrawing of life-sustaining interventions for children vary greatly while lack of education and family support increase level of stress while parents are waiting ${ }^{(16)}$.

Parents who were waiting for long time in the PICU experienced high level of anxiety and stress. Moreover, lack of knowledge of the surrounding procedures and monitors present increases parents' anxiety. Providing education and regular update to the family will help to reduce their anxiety ${ }^{(17)}$. Required information provided by health care professionals has to be appropriate and sufficient that can be comprehended by parents. Parents who speak different language than the care providers, or have low educational level need information delivered in understandable means to minimize anxiety such as by providing written materials in their mother tongue language, using communication technique or using interpreter as needed. However, informing parents how long they must wait is an efficient way to improve their affective response to the emergency situation, when the waiting time is long without justification, parents are more likely to experience anxiety and stress. Providing adequate information to parents reduced their levels of stress and anxiety significantly which inturn reduce parents' uncertainty and facilitates cognitive coping ${ }^{(18)}$.

Parents of children admitted to PICU undergo changes in response to their childs health condition, treatment, prognosis, and the involvement of parents in making decisions for childs treatment. Evaluation of parents during their children admission to PICU is needed to assess current responses to stress associated with the PICU experience and to identify parents at risk for extended physical and emotional consequences. Review of the current literature revealed only few studies were done about the relationship between waiting time, anxiety and sleep disturbance among parents of children admitted to pediatric intensive care units. Burden of hospital experience among child's parents is so high in the intensive care units as a result of the critical condition of the child that works as a trigger to increase the risk for buildingup of anxiety and sleep disturbances. Hence understanding the relationship between waiting time, anxiety and sleep disturbance among parents of children admitted to pediatric intensive care units will facilitate and can help in proposing different interventions to support the parents which 
consequently will reduce their anxiety and sleep disturbances. Additionally, fewer research evidences were found in this regard in Saudi Arabia, therefore it is an important to study the relationship between waiting time, anxiety and sleep disturbance among Saudi parents of children admitted to pediatric intensive care units in the Saudi community.

\section{Subjects and Methods}

Aim of the Study

To identify the relationship between waiting time, anxiety and sleep disturbance among saudi parents of children admitted to pediatric intensive care unit

\section{Specific Objectives}

1. Assess the level of anxiety among parents of children admitted to pediatric intensive care unit.

2. Evaluate the sleep disturbance among parents of children admitted to pediatric intensive care unit.

3. Appraise the relationship between waiting time, anxiety and sleep disturbance among parents of children admitted to pediatric intensive care unit.

\section{Secondary Objectives}

1. Evaluate the relationship between selected demographics variables and levels of anxiety, sleep disturbance and waiting time among parents of children admitted to pediatric intensive care unit.

\section{Study Area/Setting}

The research was conducted in King Abdullah specialized children hospital (KASCH), Ministry of National Guard-Health Affairs. The data will be collected in the waiting areas from parents of children admitted to pediatric intensive care unit.

\section{Study Subjects \\ Inclusion criteria: \\ 1. Parents of a child admitted to the pediatric intensive care unit (PICU). \\ 2. Ability to speak and read either Arabic or English. \\ 3. Agree to voluntarily participate in this study.}

\section{Study Design}

A cross sectional descriptive corelational study design was employed to conduct this study with the aim to examine the relationship between waiting time, anxiety and sleep disturbance among parents of children admitted to the pediatric intensive care unit, at King Abdulaziz Medical City (KAMC-R), National Guard, in the central region of the Kingdom of Saudi Arabia.

\section{Sample Size}

Using the sample size calculator software to determine the sample size for the current study from the average number of PICU admissions (about 35 patients per month) with some seasonal variations with a confidence level of $95 \%$ and confidence interval of $8 \%$ the calculated sample size was 111 . A sample of 115 adult parents of children admitted to the PICU was included in the study to ensure representativeness of the total population.

\section{Sampling Technique}

A convenience sampling technique was utilized in the current study to recruite 115 parents of children admitted to the pediatric intensive care unit, at King Abdalla Children Specialist Hospital affiliated to King Abdulaziz Medical City (KAMC-R), National Guard, in the central region of the Kingdom of Saudi Arabia considering the inclusion criteria for the study sample.

\section{Data Collection methods, instruments used, measurements}

Data was collected using three parts questionnaire survey.

Part one is the demographic data sheet, which was developed by the researchers and includes the age of child, time and type of admission, medical diagnosis and parents charactheristics such as age of accompanying parent, gender, marital status, education, occupation, number of childern, residence distance from PICU and the waiting time from reaching the unit till first seen by the physician.

Second part is the short version of Spielberger State-Trait Anxiety Inventory (STAI-6 item) ${ }^{(19)}$ is a selfreported instrument. It was designed to assess levels of anxiety through 6 items scored by a 4-point likert-scale, positive items are scored reversely (calm, relaxed, content) so $1=4,2=3,3=2$ and $4=1$. The higher score indicating greater anxiety. The STAI-6 has demonstrated acceptable reliability coefficient $(\alpha=0.82)$ and good discriminant 
validity. The six-item short-form of the STAI (STAI-6) produces scores comparable to those obtained using the full 20-item STAI. It has acceptable reliability, and produces scores that are similar to those produced with the full-form across subject groups demonstrating normal and elevated levels of anxiety while remains sensitive to different degrees of anxiety experienced by humen beings.

The third part is the Parental Sleep Disturbance Questionnairre developed by the researchers to assess the sleep pattern, hours of sleep and sleep problem of the parents of children admitted to the pediatric intensive care unit. The first section of the tool comprises of two items to assess the sleep pattern, second section has two items to assess the hours of sleep and the third section is to assess for any sleep problem to be identified from the given list of sleep problems.

The questionairre survey was translated into arabic and tested and confirmed for face validity by three experts in the area.

After obtaining all necessary ethical approvals from CON-R research unit and KAIMRC ethical committee, the principle investigator got the approval from the concerned authority of King Abdullah specialized Children Hospital (KASCH), Ministry of National Guard-Health Affairs, in order to collect the data. Data collectors explained the purpose and nature of the study to the participants and get the consent form from those parents of children admitted to the PICU who voluntarily agreed to participate in the study after ensuring confidentiality and anonymity of the collected data.

\section{Data Management and Analysis Plan}

Data was coded for entry and analysis using SPSS statistical software package version 22. Data was presented using descriptive statistics in the form of frequencies and percentages. Interval and ratio variables were presented in the form of means and standard deviations. Appropriate statistical tests was employed to test the correlation between study variables. The significance level was chosen to be $(\mathrm{p}<0.05)$.

\section{Ethical Considerations}

After obtaining all necessary ethical approvals from College of Nursing' research unit and King Abdullah International Medical Research Center' ethics committees, researcher obtained permission from the proposed setting prior to actual data gathering. Research ethics was strictly followed in pursuing the study. Written consent was obtained from each potential participant before starting the study. All information taken from the participants were considered as highly confidential and no part of this study was disclosed including the identities of the participants or their families. Privacy and confidentiality were completely protected, No identifiers or personal information were collected or stored including participant's name, IDs or others.

\section{Results}

One hundered and twenty three participants voluntrely agreed to participate in the study, age of participants ranged between 19 and 56 with a mean age of $32.38+8.35$ years. $73(59.3 \%$ were males while $50(40.7)$ were females. 112 $(91.1 \%)$ were married, $9(7.3 \%)$ were divorced and only two women were widowed. With regard to the educational level of the $15(12.2 \%)$ participants had completed the primary school, 35 (28.5\%) finished secodary school, 17 (13.8\%) completed high school, where 56 participants $(45.5 \%)$ had completed the college. 50.4\%, $(\mathrm{N}=62)$ of the participants were employeed, eight participants $(6.5 \%)$ were students, $42.3 \%(n=50)$ where unmployeed, while only nine participants $(7.3 \%)$ were retired.

The number of childern the participants have varied between one and six children with $26.8 \%$ of the participants had the only admitted child, $22 \%$ had three children, $32.5 \%$ had four children, $12.2 \%$ had five children, where the rest $6.5 \%$ had six children. The distance from home to hospital ranged between 2 and 400 kilometers. The age of the admitted children ranged from months (less than one year) to 14 years old with more than half of the children $(60.1 \%)$ aged 4 years and younger. The type of admission was assesed and results of the current study revealed that 67 children $(54.5 \%)$ were admitted for acute illness, six children $(4.8 \%)$ were admitted for planned surgeries, 23 children $(18.7 \%)$ admitted to the hospital for trauma and the other $22 \%(n=27)$ of admissions were for diagnosis of chronic ilness. The medical diagnosis of the admitted childern differs among all admited children with the most frequently reported diagnins was pneumonia $(\mathrm{N}=34,27.6 \%)$ followed by meningitis $(\mathrm{n}=24,19.5 \%)$.

Number of the days of admission ranged between one day and 22 days with a mean legth of hospitalization of $5.09 \pm 3.42$ days. The waiting time that the patients and their family waited until thay received the care varied between 5 and 120 minutes with a mean waiting time of $34.27 \pm 22.56$ minutes. 
Table 1: Demographic Characterstics of the Participants $(N=123)$

\begin{tabular}{|c|c|c|}
\hline Variable & Frequency $(\mathrm{N})$ & Percent $(\%)$ \\
\hline Gender & & \\
\hline Male & 73 & 59.3 \\
\hline Female & 50 & 40.7 \\
\hline Marital Status & & \\
\hline Married & 112 & 91.1 \\
\hline Divorced & 9 & 7.3 \\
\hline Widowed & 2 & 1.6 \\
\hline Level of Education & & \\
\hline Elementary education & 15 & 12.2 \\
\hline Secondary education & 35 & 28.5 \\
\hline High school & 17 & 13.8 \\
\hline University education & 56 & 45.5 \\
\hline Occupation & & \\
\hline Student & 8 & 6.5 \\
\hline Employed & 56 & 45.5 \\
\hline Unemployed & 50 & 40.7 \\
\hline Retired & 9 & 7.3 \\
\hline Type of Admission & & \\
\hline Planned surgery & 6 & 4.8 \\
\hline Acute illness & 67 & 54.5 \\
\hline Trauma & 23 & 18.7 \\
\hline Chronic illness & 27 & 22.0 \\
\hline
\end{tabular}

Table 2 presents the participants' responses to Spielberger State-Trait Anxiety Inventory. The total participants' scale score ranged between 9 and 23 with a mean score of $13.33+3.55$ and median score of 12 . More than half of the participants $(n=77,62.6 \%)$ scored 12 and above reflecting considerable levels of anxiety.

Table 2: Participants Responses to Spielberger State-Trait Anxiety Inventory $(\mathbf{N}=\mathbf{1 2 3})$

\begin{tabular}{|c|c|c|c|c|}
\hline Feelings & $\begin{array}{l}\text { Not at all } \\
\text { N (\%) }\end{array}$ & $\begin{array}{c}\text { Somewhat } \\
\text { N (\%) }\end{array}$ & $\begin{array}{c}\text { Moderately } \\
\text { N (\%) }\end{array}$ & $\begin{array}{c}\text { Very much } \\
\text { N }(\%)\end{array}$ \\
\hline 1. I feel calm & $33(26.8 \%)$ & $50(40.7 \%)$ & $9(7.3 \%)$ & $31(25.2 \%)$ \\
\hline 2. I am tense & $41(33.3 \%)$ & $25(20.3 \%)$ & $32(26.0 \%)$ & $24(20.3 \%)$ \\
\hline 3. I feel upset & $79(64.2 \%)$ & $18(14.6 \%)$ & $18(14.6 \%)$ & $8(6.5 \%)$ \\
\hline 4. I am relaxed & $26(24.4 \%)$ & $25(20.3 \%)$ & $42(34.1 \%)$ & $30(24.4 \%)$ \\
\hline 5. I feel content & $36(29.3 \%)$ & $18(14.6 \%)$ & $23(18.7 \%)$ & $46(37.4 \%)$ \\
\hline 6. I am worried & $42(34.1 \%)$ & $64(52.0 \%)$ & $0 \%$ & $17(13.8 \%)$ \\
\hline
\end{tabular}

Table 3: Participants Responses to Parental Sleep Disturbance Questionnaire (n=123)

\begin{tabular}{|l|c|c|}
\multicolumn{1}{|c|}{ Sleep Problem } & $\begin{array}{c}\text { Yes } \\
\mathbf{N}(\mathbf{\%})\end{array}$ & $\begin{array}{c}\text { No } \\
\mathbf{N}(\%)\end{array}$ \\
\hline \hline- Difficulty falling asleep & $107(87.0 \%)$ & $16(13.0 \%)$ \\
\hline- Wake up in the middle of the night & $114(92.7 \%)$ & $9(7.3 \%)$ \\
\hline- Difficulty resuming sleep after waking up & $105(85.4 \%)$ & $18(14.6 \%)$ \\
\hline- Wake up in the early morning & $114(92.7 \%)$ & $9(7.3 \%)$ \\
\hline- Have bad dreams/nightmares & $36(29.3 \%)$ & $87(70.7 \%)$ \\
\hline
\end{tabular}

Parents were asked five questions to assess their experience of any sleep disturbances that developed as a result of admission of their child to the PICU. A very significant precentage of the parents reported sleep problems including waking up in the middle of the night and wake up in the early morning $(n=114,92.7 \%)$ followed by difficulty falling asleep $(n=107,87.0 \%)$, difficulty resuming sleep after waking up $(n=105,85.4 \%)$ and around one thid of the participants $(n=36,29.3 \%)$ reported having bad dreams. Overall almost three quarters of the participants in this study $(\mathrm{n}=90,73.2 \%)$ mentioned that these sleep problems affected them negatively, table3.

As presented in table 4 there is a significant change in the parents' sleep pattern and hours of daily sleep before and after the admission of their children to the PICU. One sample t test showed a statistically significant difference in how parents described their daily sleep pattern prior and after admission of their children to PICU $(\mathrm{t}=49.299, \mathrm{p}=0.000)$. Daily sleep hours prior and after the child's admission to PICU changes dramatically as demonstrated by the calculated test $(\mathrm{t}=32.560, \mathrm{p}=0.000)$. 
Table 4: Participants Responses to Parental Sleep Disturbance Prior and After Child Admission to the $\operatorname{PICU}(\mathbf{n}=\mathbf{1 2 3})$

\begin{tabular}{|c|c|c|c|c|}
\hline Statement & $\begin{array}{l}\text { Very good } \\
\text { N }(\%)\end{array}$ & $\begin{array}{l}\text { Satisfactory } \\
\text { N }(\%)\end{array}$ & $\begin{array}{l}\text { Poor } \\
\text { N }(\%)\end{array}$ & $\begin{array}{l}\text { Very } \\
\text { poor } \\
\text { N }(\%)\end{array}$ \\
\hline \multicolumn{5}{|l|}{ Sleep Pattern } \\
\hline $\begin{array}{l}\text { 1. Overall, How would you describe your daily } \\
\text { sleep pattern prior to your child's admission to } \\
\text { PICU }\end{array}$ & $85(69.1 \%)$ & $30(24.4 \%)$ & $0 \%$ & $8(6.5 \%)$ \\
\hline $\begin{array}{l}\text { 2. Overall, How would you describe your daily } \\
\text { sleep pattern since your child's admission to } \\
\text { PICU }\end{array}$ & $17(13.8 \%)$ & $8(6.5 \%)$ & $\begin{array}{c}83 \\
(67.5 \%)\end{array}$ & $\begin{array}{c}15 \\
(12.2 \%)\end{array}$ \\
\hline \multicolumn{5}{|c|}{$\mathrm{t}=49.299, \mathrm{p}=0.000$} \\
\hline \multicolumn{5}{|l|}{ Hours of Sleep } \\
\hline $\begin{array}{l}\text { 3. Daily sleep hours prior to your child's admission } \\
\text { to PICU }\end{array}$ & $\begin{array}{l}\text { Less than } 6 \\
\text { hrs/day } \\
65(52.8 \%) \\
\end{array}$ & $\begin{array}{c}6-8 \\
\mathrm{hrs} / \mathrm{day} \\
58(47.2 \%) \\
\end{array}$ & \multicolumn{2}{|c|}{$\begin{array}{l}\text { More than } 8 \text { hrs/day } \\
0 \%\end{array}$} \\
\hline $\begin{array}{l}\text { 4. Daily sleep hours since your child's admission to } \\
\text { PICU }\end{array}$ & $\begin{array}{l}\text { Less than } 6 \\
\text { hrs/day } \\
123(100 \%)\end{array}$ & $\begin{array}{c}6-8 \\
\text { hrs/day } \\
0 \%\end{array}$ & \multicolumn{2}{|c|}{$\begin{array}{l}\text { More than } 8 \mathrm{hrs} / \text { day } \\
0 \%\end{array}$} \\
\hline
\end{tabular}

In assessing the relationship between selected variables and anxiety score, Pearson $r$ revealed only a highly statistically significant relationship between anxiety score and distance from home to hospital $(\mathrm{r}=0.374, \mathrm{p}=0.000)$ and length of child hospitalization $(\mathrm{r}=0.238, \mathrm{p}=0.008)$. No significant relationship between anxiety score and age of the parent $(\mathrm{r}=0.038, \mathrm{p}=0.679)$, age of the sick child $(\mathrm{r}=0.115, \mathrm{r}=0.203)$ and number of children $(\mathrm{r}=0.095, \mathrm{p}=0.295)$ were found in this study.

Table 5: Relationship between Participants' Gender and Anxiety Scores $(\mathrm{n}=123)$.

\begin{tabular}{|l|c|c|c|c|}
\hline \multicolumn{1}{|c|}{ Variable } & M & SD & t & p \\
\hline Male (73) & 13.21 & 4.136 & 0.481 & 0.631 \\
Female (50) & 13.52 & 2.476 & & \\
\hline
\end{tabular}

As presented in table 5, the independant t test revealed no significant difference between male and female participants in relation to their total scores of anxiety scales $(p=0.63)$

One-way ANOVA was conducted to determine if anxiety scores were different for groups with different martital status. Participants were classified into four groups: married $(n=112)$, divorced $(n=9)$ and widowed (n $=2$ ). There was no statistically significant difference between groups in relation to anxiety scores as determined by one-way ANOVA $(\mathrm{F}=1.297, \mathrm{p}=0.277)$.

A highly statistically significant difference between groups with different educational background in relation to anxiety scores was determined by one-way ANOVA $(\mathrm{F}=4.476, \mathrm{p}=0.004)$ where parents who finished their college education had higher anxiety scores compared to those parents with lower educational acheivements.

Unemployed participants experienced significantly higher anxiety scores compared to employed and retired participants as evidenced by One-way ANOVA $(\mathrm{f}=4.335, \mathrm{p}=0.01)$. Reason for child

admission had an impact on the anxiety score reported by the participants with the parents of children admitted for acute illnesses reported higher anxiety scores compared to those parents of children admitted for truama, schedualed surgery or chronic illnesses $(\mathrm{f}=5.563, \mathrm{p}=0.005)$.

Pearson $r$ was conducted to determine the relationship between waiting times in the emergency department before seeing the health care provider and the parents' anxiety scores and revealed a highly statistically significant relationship between the two variables as the anxiety scores were higher among those parents who spent longer time waiting in the emergency department $(\mathrm{r}=0.290, \mathrm{p}=0.001)$

\section{Discussion}

The results of this study stipulated an intuition into the parents' experience of their child's admission to a pediatric intensive care unit. This exploratory study focused on relationship between waiting time, anxiety and sleep disturbance among Saudi parents of children admitted to pediatric intensive care unit. Parents during the admission of their child to PICU for a critical illness will have severe anxiety which is likely affected by factors other than their child's illness such as their support network, family dynamics, and the impact of child's hospitalization on parents' employment. This time is one that requires effective communication from medical professionals about the child's condition, further evaluation and treatment ${ }^{(20)}$.

The first objective was to examine the level of anxiety among parents of children admitted to paediatric 
intensive care unit. The participants' responses to Spiel Berger State-Trait Anxiety Inventory scale score ranged between 9 and 23. More than half of the participants scored 12 and above reflecting considerable levels of anxiety. The results of this study suggests that parents of children admitted to PICU have high anxiety in the first 24 hrs. This finding is supported by another study in which they explored that for parents, admission of their child to a pediatric intensive care unit (PICU) is a traumatic experience, because of several reasons like ambiguous outcome, visualizing many equipment's and painful procedures. This study addressed that intensive care setting is a busy and fearsome place conquered by sick children, medical professionals, advanced medical equipment's, bright lights and shrill monitors. In the beginning, parents might experience extreme levels of anxiety that approach nearpanic level, followed by a lessening of anxiety in the subsequent days ${ }^{(20)}$.

In a study on parental stressors from Ludhiana, India, found that there is significant stress among parents of children admitted in PICU ${ }^{(6)}$, where the average parental stress score was 3 . In another study the average parental stress score was 3.5, which points out there is significant stress, as well as it was witnessed that parents seeing their child being unresponsive, other sick children in PICU, crises in other children in the PICU increased parental stress ${ }^{(20)}$. While considering the procedures being done as a part of treatment to the child, Haines and Childs ${ }^{(21)}$ explored that higher acuity of children who require mechanical ventilation is associated with the need for more invasive therapies (central lines, chest tubes, etc), and these procedures may be significant contributors to parental anxiety. Studies have demonstrated that as parental stress and anxiety increase, the likelihood of treatment adherence for the child decreases ${ }^{(22)}$

Second objective of the study was to evaluate the sleep disturbance among parents of children admitted to pediatric intensive care unit. A very significant percentage of the parents reported sleep problems including waking up in the middle of the night and wake up in the early morning, followed by difficulty falling asleep, difficulty resuming sleep after waking up and around one third of the participants reported having bad dreams. Overall almost three quarters of the participants in this study mentioned that these sleep problems affected them negatively. Experiencing high stress on a daily basis may affect emotions and sleep negatively ${ }^{(23)}$. Furthermore, there is a substantial alteration in the parents sleep pattern and hours of daily sleep previously and after the admission of their children to the PICU. This finding is supported with the results of another study in which they found that $93 \%$ of mothers and $60 \%$ of fathers reported sleep disturbance ${ }^{(24)}$. Sleep disturbances affect functions needed for problem-solving and emotional regulation ${ }^{(25)}$. Daytime weariness and hang-up of mental clarity may increase due to lack of effective sleep ${ }^{(26)}$. As the major caregivers, the mothers have more sleep disturbance than the fathers. In long term, the parents' health can become a causative factor of stress, anxiety, and sleep disturbance, jeopardizing the marital relationships and family dynamics.

Several factors were associated with parents' anxiety, one among them is the waiting time. In this study the waiting time that the parents and their family of the child until they received the care varied between 5 and 120 minutes. There is limited studies exploring the relation between anxiety among parents of children admitted to PICU and their waiting time, A research study tried to explain about the perception of parents, they expressed that the time at the PICU was like being in another world, which gave them feeling of unreality. The time they spent waiting for information is permeated with anguish, fear, and anxiety ${ }^{(27)}$.

Hospitalized children demand more supervision and care, making sleep disturbance a common challenge among these parents. Sufficient amount of sleep and rest was described as vital for parental functioning. Daily hours of sleep and sleep pattern of parents of children admitted to PICU in this study was found to have a significant difference before and after the admission of their children to the PICU. This finding is similar to the findings of a study that identified that majority of the parents experienced sleep problems after their children were admitted to the PICU. It was found that Mothers had greater sleep disturbances than did fathers. Parental stress, and fatigue was related to subjectively reported sleep disturbances ${ }^{(24)}$. A qualitative study revealed that parents of children in PICU was uncomfortable and expressed problems regarding sleep ${ }^{(28)}$. Different factors were explored in their study among parents of children admitted to PICU regarding their experiences of sleep and rest. The study finding explored three main theme Factors influencing sleep and rest, they were environmental factors related to experiences such as disturbing sounds and uncomfortable beds, interpersonal factors defined how supportive the relations with spouses, relatives, nurses, and doctors were experienced as strengthening the parental confidence and helping parents to relax and organizational factors, like how continuous information about the child's care and prognosis was informed to the parents which in turn made parents to feel secure and calm thus supporting parental sleep and other basic needs. By enhancing parents' sleep and rest in the hospital, would greatly relieve parents' stress.

In assessing the relationship between selected variables and anxiety, it was found that a highly statistically significant difference between groups with different educational background in relation to anxiety, parents who finished their college education had higher anxiety scores compared to those parents with lower educational achievements. Consistent with the current study a researcher explained that parent's education has an impact on anxiety level of parents of children admitted to PICU. If parents are educated they can be provided with informations about the child's expected progress, which may alter parental anxiety by reassuring them about the 
likelihood of their child's recovery. Unemployed parents experienced significantly higher anxiety scores compared to employed and retired parents ${ }^{(29)}$. Earlier a study discovered that parental anxiety is likely affected by factors other than their child's illness such as their support network, family dynamics, and the impact of child's hospitalization on parents' employment. Reason for child's admission had an impact on the anxiety reported by the parents, parents of children admitted for acute illnesses was identified with higher anxiety compared to those parents of children admitted for trauma, scheduled surgery or chronic illnesses ${ }^{(7)}$. An interesting trend was observed among parents whose children had chronic medical conditions. Among parents with high Trait Anxiety, a majority of them were parents of chronically ill children. Studies have shown a relationship between chronic medical conditions and parental adjustment difficulties and quality of life (26-28). Waiting time is one of the most frequently mentioned concerns of parents. This study results revealed that relationship between waiting times in the emergency department before seeing the health care provider and the parents' anxiety scores was highly statistically significant ${ }^{(30)}$. A qualitative study revealed that identifying and fulfilling the needs of parents during admission of their children to PICU without prolonged waiting time will help to reduce the negative effects of stress and anxiety ${ }^{(28)}$.

There is significant stress among parents of children admitted to PICU, and the factors influencing anxiety differs from other studies done elsewhere. Many of these factors can be looked into and remedial steps can be taken to relieve some of these stressors. However further longitudinal studies are required to assess the deeper concerns and other psychological aspects of parents whose children are admitted in PICU.

\section{Conclusion and Recommendations}

The findings of this exploratory study indicate considerable levels of anxiety and changes in sleep pattern of parents of children admitted to paediatric intensive care unit. The pediatric intensive care unit (PICU) has long been renowned as an emotionally charged and highly distressing place. Admission of a child to the pediatric intensive care unit (PICU) can create high-parental anxiety, which in turn affects both patients and family members. Consequently, the family members of a child in the PICU experience moderate anxiety during admission. Anxiety is more conspicuous for both parents of an acutely ill child, but mothers of chronically ill children may need more emotional support during admission of the child to PICU. During this period, identifying the parental needs and the causes of anxiety might contribute to parents' mental health.

\section{Based on the findings of this study, the following recommendations are suggested:}

- $\quad$ Parents ought to have the option of staying with the child at all times, especially during procedures, tests, and resuscitations, this will help in reducing parental anxiety.

- An expanded training in communication skills, can be instituted to the nurses and other members of the health care team in PICU.

- Formal education placing a greater emphasis on communication and basic clinical skills at an undergraduate level that supports the integration of emergency nursing content and clinical experiences into nursing curricula.

- Consider the PICU setting and engage the health care professionals who are at the front line of care for critically ill children and their families.

- Screening of parents at high risk for anxiety and implementing interventions to reduce uncertainty and maladaptive coping strategies may be beneficial.

\section{- $\quad$ Funding}

This research received no specific grant from any funding agency in the public, commercial, or not-for-profit sectors.

\section{- Conflict of Interests}

The authors declare that they have no conflict of interests with any organization regarding the materials discussed in this manuscript.

\section{- Acknowledgment}

The authors would like to extend their thanks and appreciations to all participants who voluntarily participated in the study and shared their experience.

\section{Bibliographic References}

1. Kumar BS, Avabratha S. Parental stress: a study from a pediatric intensive care unit in Mangalore. internationa http://dx.doi.org/10.18203/2349-3291.ijc.

2. Margaret SM, Melba CC, Charlotte S, Ruthstephenson H. Maternal and Paternal Stress Reactions when a Child is Hospitalized in a Pediatric Intensive Care Unit. Comprehensive child and Adolescent Nursing. 2009; 7(6), 333-342.

3. Ministry of Health, KSA. (1437 Hejra). Retrieved from Statistical YearBook: 
https://www.moh.gov.sa/ministry/statistics/book/pages/default.aspx

4. Meyer EC, Snelling LK, Myren-Manbeck LK. Pediatric Intensive Care: The Parents' Experience. Advanced critical care. 1998; 9(1), 64-74. doi:1998;9(1):64-74.

5. Jee RA, Shepherd JR, Boyles CE, Ross OC. Evaluation and comparison of parental needs, stressors, and coping strategies in a pediatric intensive care unit. Pediatric Critical Care Medicine. 2012; 13(3), 165-72. doi:DOI: 10.1097/PCC.0b013e31823893ad.

6. Pooni PA, Singh D, Bains HS, Misra BP, Soni RK. Parental stress in a paediatric intensive care unit in Punjab, India. Journal of pediatrics and child health. 2013; 49(3), 204-209. doi:DOI: 10.1111/jpc.12127.

7. Needle JS, O'Riordan M, Smith PG. Parental anxiety and medical comprehension within 24 hrs of a child's admission to the pediatric intensive care unit. Pediatric Critical Care Medicine. (2009); 10(6), 668-674. doi:10.1097/PCC.0b013e3181a706c9.

8. McCann D. Sleep Deprivation Is an Additional Stress for Parents Staying in Hospital. Journal for Specialists in Pediatric Nursing. 2008, April; 13(2), 111-122. doi:10.1111/j.1744-6155.2008.00142.x.

9. McLoone J, Wakefield C, Yoong S, Cohn R. Parental sleep experiences on the pediatric oncology ward. Supportive Care in Cancer. 2013; 21(2), 557-564. doi:10.1007/s00520-012-1547-z

10. Stremler R, Dhukai Z, Pullenayegum E, Weston J, Wong L, Parshuram C. Sleep, Sleepiness, and Fatigue Outcomes for Parents of Critically Ill Children. Pediatric Critical Care Medicine. 2014; 15(2), e56-e65. doi:10.1097/01.pcc.0000436198.15337.15.

11. Ahmed S, Manaf NH, Islam R. Effects of Lean Six Sigma application in healthcare services: a literature review. pupmed, 189-94. doi:10.1515/reveh-2013-0015.

12. Corsano PM, Vignola V, Guidott L, Izzi G. he waiting room as a relational space: youngpatients and their families' experience ina day hospital. child :health care and development. 2015; 1066-73.

13. Meert K, Thurston C, Briller S. The spiritual needs of parents at the time of their child's death in the pediatric intensive care unit and during bereavement: a qualitative study. Pupmed. 2005; 420-7.

14. Devlin A, Andrade C, Carvalho D. Qualities of Inpatient Hospital Rooms: Patients' Perspectives. Health Environments Research \& Design Journal. (2016); Vol. 9 (3) 190-211.

15. Abbas SA, Virginia P, Rosemary C, Anthony O. Families' needs of critical care Muslim patients in Saudi Arabia: a quantitative study. BACN Nursing in Critical Care. 2013;19 (4), 185-195.

16. Annie J, Keith B, Barbara F. Communication with parents concerning withholding or withdrawing of lifesustaining interventions in neonatology. Sciencedirect. 2014; Volume 38, Issue 1.

17. Dahav P1, Sjöström S. Parents' experiences of their child being admitted to a paediatric intensive care unit: a qualitative study-like being in another world. Scand J Caring Sci. 2017; DOI 10.1111/scs.12470.

18. Frederic E, Johan S, Rolf W, Cyrille D. Improving Patients Experience in Peadiatric Emergency Waiting Room. 2016; doi:10.3233/978-1-61499-658-3-535, 573.

19. Marteau TM, Bekker H. The development of a six-item short-form of the state scale of the Spielberger StateTrait Anxiety Inventory (STAI). British Journal of Clinical Psychology. 1992; 31:301-306.

20. Binoop KS, Shreedhara KA. Parental stress: a study from a pediatric intensive care unit in Mangalore, Int J Contemp Pediatr. 2015 Nov;2(4):401-405.

21. Haines C, Childs H. Parental satisfaction with paediatric intensive care. Paediatr Nurs. (2005); 17:37-41.

22. Balluffi A, Kassam-Adams N, Kazak A, Tucker M, Dominguez T, Helfaer M. Traumatic stress in parents of children admitted to the pediatric intensive care unit. Pediatr Crit Care Med. 2004; 5:547-53.

23. Åkerstedt T, Orsini N, Petersen H, Axelsson J, Lekander M, Kecklund G. Predicting sleep quality from stress and prior sleep-A study of day-to-day covariation across six weeks. Sleep Medicine. 2012; 13, 674-679.

24. Lee SY, Lee KA, Rankin SH, Weiss SJ, Alkon, A. Sleep disturbance, fatigue, and stress among ChineseAmerican parents with ICU hospitalized infants. Issues Ment Health Nurs. 2007 Jun; 28(6):593-605.

25. Medina AM, Lederhos CL, Lillis TA. Sleep disruption and decline in marital satisfaction across the transition to parenthood. Families, Systems, \& Health. 2009; 27(2), 153-160.

26. Edéll-Gustafsson, U, Angelhoff C, Johnsson E, Karlsson J \& Mörelius E. Hindering and buffering factors for parental sleep in neonatal care. A phenomenographic study. Journal of Clinical Nursing. 2015; 24(5-6), 717727.

27. Santos LM, Oliveira VM, Santana RCB, Fonseca MCC, Neves ES, Santos MCS. Maternal experiences in the Pediatric Intensive Care Unit. R Pesq. 2017;5(1):3432-42.

28. Dilek B, Gülçin, G, Gonca KM. A Qualitative Study Exploring the Needs of Turkish Mothers in the Pediatric Intensive Care Unit, J Pediatr Res. 2018;5(4):187-193.

29. Alaradi, Maryam Isa, "Predictors of uncertainty, stress, anxiety, and depressive symptoms of parents of preterm infants in the neonatal intensive care unit.". Electronic Theses and Dissertations. 2014; Paper 25. https://doi.org/10.18297/etd/25.

30. Chiejina E, Ebenebe R, Odira C. Relationships between parental demographic variables and parental stress over their hospitalized infants in NICU. Global Advanced Research Journal of Educational Research and 
Review. 2014; 3(3), 72-78.

Contact Information of the Corresponding Author

DR. EMAN DAWOOD, RN, B.Sc.N., M.Sc.N., PhD

Professor - Psychiatric and Mental Health Nursing

Chairperson Scholarship Unit

College of Nursing-Riyadh

King Saud bin Abdulaziz University for Health Sciences (www.ksau-hs.edu.sa)

King Abdulaziz Medical City, Ministry of National Guard Health Affairs

Mail Code 3105

P.O.Box.3660 Riyadh, 11481

Kingdom of Saudi Arabia 